\title{
Spatially Resolved Experimental and Numerical Investigation of the Flow through the Intake Port of an Internal Combustion Engine
}

\author{
Frank Hartmann $^{1 *}$, Stefan Buhl ${ }^{1}$, Florian Gleiss ${ }^{1}$, Philipp Barth ${ }^{2}$, Martin Schild ${ }^{2}$, \\ Sebastian A. Kaiser ${ }^{2}$ and Christian Hasse ${ }^{1}$ \\ ${ }^{1}$ Chair of Numerical Thermo-Fluid Dynamics, TU Bergakademie Freiberg, Fuchsmühlenweg 9, 09599 Freiberg - Germany \\ 2 Institute for Combustion and Gas Dynamics, University of Duisburg-Essen, Lotharstraße 1, 47057 Duisburg - Germany \\ e-mail: frank.hartmann@iec.tu-freiberg.de - sebastian.kaiser@uni-due.de \\ * Corresponding author
}

\begin{abstract}
Modern spark-ignited internal combustion engines have intake ports designed to introduce high levels of so-called "tumble" charge motion. Correspondingly high shear rates can lead to high fluctuations and turbulence within the combustion chamber. A suitable test case to characterize the intake flow is a steady-state flow bench. Although routinely used in the engine development process to determine the global discharge coefficients, only a few detailed numerical and experimental studies use this test case to analyze the flow in the vicinity of the valve with high spatial and temporal resolution. In this paper, we combined highly resolved two-dimensional, two-component Particle Image Velocimetry (PIV) measurements and numerical simulations using a Detached-Eddy Simulation (DES) model to characterize engine-relevant flow features on a flow bench. The spatial resolution of numerical simulations on two different grids is assessed and compared to that of the PIV measurement. The results of simulations and experiment are then compared in terms of their mean and fluctuation velocity fields and the jet orientation. A detailed study of the area around the valve seats investigates the validity of wall functions in this region. Finally, we examine structures induced by vortex-shedding at the valve stem and if they are transported into the combustion chamber.
\end{abstract}

Résumé - Étude numérique et expérimentale résolue dans l'espace de l'écoulement à travers le conduit d'admission d'un moteur à combustion interne - Les moteurs à combustion interne modernes à allumage commandé disposent de conduits d'admission conçus pour générer des niveaux importants de mouvements de charge dits «tumble». Les niveaux importants de taux de cisaillement qui en résultent peuvent conduire à de fortes fluctuations et turbulences dans la chambre de combustion. Un cas test adapté pour caractériser l'écoulement d'admission est un banc volute. Bien que son utilisation durant les phases de conception moteur pour déterminer les coefficients de perte de charge globaux soit très répandue, seules quelques études numériques et expérimentales détaillées utilisent ce test pour étudier l'écoulement au voisinage de la soupape avec des résolutions spatiales et temporelles élevées. Dans le présent article, nous avons combiné des mesures PIV bi-composants, bidimensionnelles hautement résolues et des simulations numériques utilisant une approche de type «Detached-Eddy Simulation » pour caractériser des structures d'écoulement d'importance pour le moteur sur un banc volute. La résolution spatiale des simulations numériques est évaluée sur deux maillages et comparée à celle de la mesure "Particle Image Velocimetry », PIV. Les résultats numériques et expérimentaux sont ensuite comparés en termes de champ de vitesse moyen et 
fluctuant et d'orientation des jets. Une étude détaillée du siège de soupape est réalisée pour vérifier la validité de lois de paroi dans cette zone. Enfin, nous examinons les structures induites par les détachements tourbillonnaires autour de la tige de soupape et si elles sont transportées dans la chambre de combustion.

\section{INTRODUCTION}

The intake jet is the main contributor to the kinetic energy of the internal combustion engine's in-cylinder flow. Thus, it is primarily responsible for the development of the flow pattern in the compression stroke and during combustion. During the intake stroke, the intake valves throttle the incoming gas flow and induce high velocities in the valve gap. Towards the combustion chamber, the resulting jet separates from the valve seat and lip creating shear layers with large gradients generating turbulence [1]. During an engine cycle, the penetrating jet transports momentum through the valve gap into the combustion chamber, which initiates large-scale motions at the beginning of the compression stroke [2].

Modern spark-ignited internal combustion engines are characterized by high levels of intake-induced in-cylinder flow, organized into a large-scale motion usually called "tumble". Such high levels of charge motion are achieved by flat intake ports and machined edges upstream of the valve seat. These measures yield a non-uniform distribution of the mass flow over the intake valve, creating the distinctive tumble motion.

In the past, there have been several investigations of the global in-cylinder flow and studies of the local flow-field near the intake port. On the one hand, steady-state experiments on flow benches were performed to investigate the flow physics in a simplified configuration [3]; on the other hand, optically accessible engines were used for measurements with more realistic boundary conditions [4]. A small number of studies investigate the flow field in or near the valve gap in detail. Schlieren cinematography, which is based on density gradients, was applied to qualitatively image the intake jet's motion within the cylinder of a transparent research engine [5]. Weclas et al. [6] used Laser Doppler Anemometry (LDA) to acquire quantitative pointwise information on the velocity and its fluctuations in the valve gap. In a second publication, the same authors [7] discussed the flow separation in the intake valve gap in steady and transient flows under engine-like conditions. Measurements were performed using LDA and hot-wire anemometry. In later studies, Particle Image Velocimetry (PIV) was applied in engine geometries to measure two velocity components instantaneously, spatially resolved within a plane defined by the laser sheet [8]. In principle, with stereoscopic PIV, the out-of-plane velocity component is also accessible [9]. "High-speed" PIV allows time-resolved investigations of in-cylinder flow structures and their development within a single cycle, while tomographic PIV enables volumetric measurements [10]. The mean threedimensional flow in the intake port was fully quantified using Magnetic Resonance Velocimetry (MRV) by Freudenhammer et al. [11].

On the other hand, a very limited number of numerical investigations of the intake flow in such flow-bench scenarios were performed. Mclandress et al. [12] compared PIV measurements and simulations on a flow bench using the KIVA-3 code. Similar studies were performed by Inagaki et al. [13] using Large-Eddy Simulations (LES) with a mixed-time-scale subgrid-scale model, which were compared to experiments and RANS simulations.

Despite the relevance of the intake flow on the charge motion and the subsequent combustion process, no combined experimental-numerical studies using state-of-the-art approaches in both areas, namely highly resolved PIV and scale-resolving flow simulations, respectively, have been reported.

This work aims to start filling this gap by applying a combination of PIV and LES, both at relatively high spatial resolution, to the flow through the intake port on a flow bench. In the following section, the experiment will be described including flow bench, camera, laser system and image acquisition. The quality and reliability of the PIV data is assessed based on the primary peak ratio of the underlying cross-correlation. The simulation's general approach and grids are discussed next. In the results, we first compare the mean velocity fields in simulation and experiment. Further investigations on the boundary layer on the valve seat evaluate the widely-used assumption of a logarithmic wall function. Finally, large structures close to the intake valve and the jet-flapping are examined in order to investigate whether such instationary structures survive the acceleration through the valve gap, which in an operating engine could have an effect on the stability of the in-cylinder flow.

\section{EXPERIMENT}

\subsection{Flow Bench}

The head of an optically accessible single-cylinder engine [14] is mounted on a steady-state flow bench. In previous investigations, this flow bench was used to determine the 


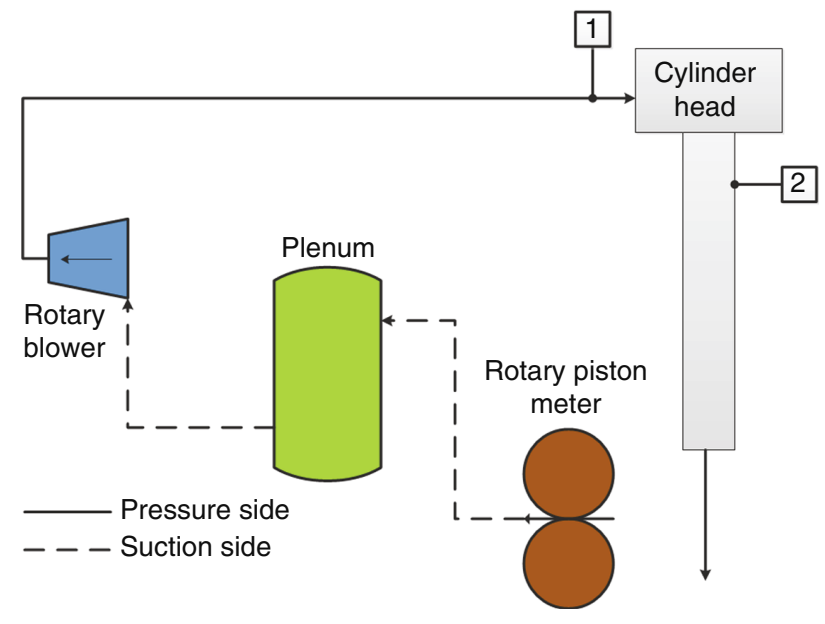

Figure 1

Flow diagram of the flow-bench with the two measurement points for pressure.

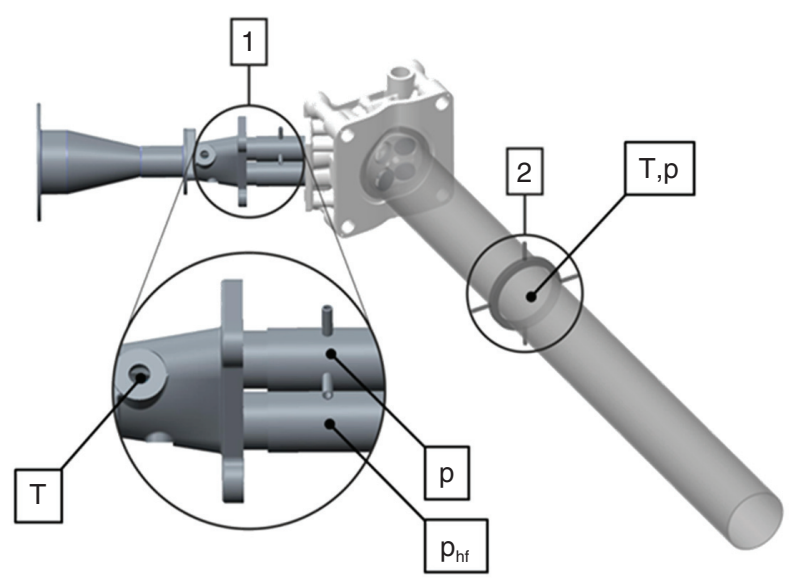

Figure 2

CAD rendering of intake system, cylinder head, and measurement tube. cylinder head's discharge coefficients to be used in onedimensional engine simulations [15]. The arrangement is shown in Figure 1. A rotary blower, powered by a speedcontrolled Alternating Current (AC) motor, provides the pressure difference which drives the flow. On the suction side of the blower, a rotary piston meter measures the volume flow. The temperature measured at the intake of this meter and the atmospheric pressure are used to calculate the mass flow. A plenum of approx. $500 \mathrm{~L}$ downstream of the piston meter eliminates flow fluctuations caused by the blower.

The cylinder head is located on the pressure side of the blower. The PVC piping upstream of the head is straight, smooth-walled, and with no change in its inner diameter $(d=76.6 \mathrm{~mm})$ for $2840 \mathrm{~mm}(37 \mathrm{~d})$. A conical adapter connects the cylinder head with its intake system, which is different in diameter, to the piping of the flow bench. Figure 2 shows the geometry of the head with the components immediately up- and downstream. In the laboratory frame, the whole assembly lies on its side on an optical table. Nevertheless, throughout this paper we will refer to the orientation of the cylinder head, valve, and flow as if the head were mounted upright with the valves above the combustion chamber, as in a typical automotive application.

In this work, a valve lift of $5 \mathrm{~mm}$ is fixed by a micrometer screw pushing onto the valve cups. Only the intake port is examined and the exhaust valves are closed. An acrylic tube with an inner diameter of $84 \mathrm{~mm}$ corresponding to the bore of the engine is placed below the cylinder head as optically accessible "cylinder walls". With an overall length of $950 \mathrm{~mm}$ from the pent-roof to the outlet, it provides an oriented outflow into the ambient air. At two locations, the temperature $T$ and relative pressure $p$ are measured: in the intake runners (reference point 1) and in the measurement tube (reference point 2, Fig. 2). Additionally, at point 1, the pressure is measured with a fast pressure transducer (Kistler 4049A5) to monitor for potential high-frequency fluctuations in the flow. For the measurements presented here, only reference point 2 (and the upstream volume flow rate) is required to define the boundary conditions, but point 1 enables data cross-check.

\subsection{Velocity Measurements}

In the vertical intake-valve plane, the two in-plane components of the instantaneous velocity field were measured by high-resolution PIV (2D-2C-PIV). Figure 3 illustrates the geometry of the optical access on the flow bench with the engine head, the location of the laser light sheet, and the imaged Region Of Interest (ROI).

For PIV, the intake air was seeded with Di-Ethyl-Hexyl-Sebacate droplets (DEHS, nominal diameter: 0.2-0.3 $\mu \mathrm{m}$ ). The aerosol droplets were generated by a nebulizer with a Laskin nozzle design [16] (LaVision, Göttingen). To ensure that the particle were homogeneously distributed, the droplets were injected through four nozzles located $500 \mathrm{~mm}$ upstream of the intake valves. The field of view was illuminated by a dual-cavity, double-pulsed Nd:YAG laser (Litron) at $532 \mathrm{~nm}$ with an energy of $30 \mathrm{~mJ} /$ pulse. A telescopic lens arrangement formed a light sheet of $0.5 \mathrm{~mm}-0.9 \mathrm{~mm}$ thickness, entering the ROI diagonally from below the head. 
a)

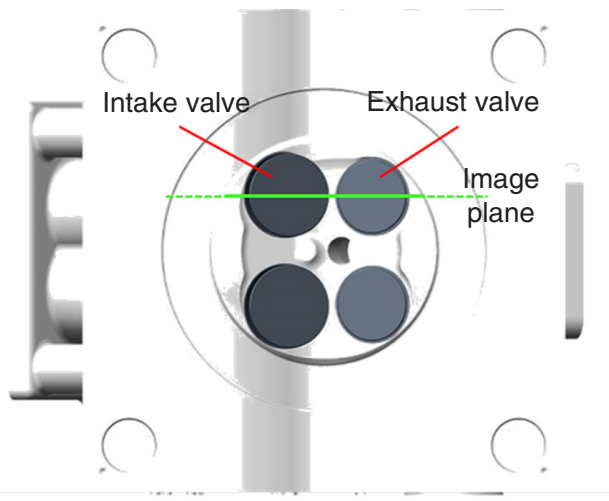

b)

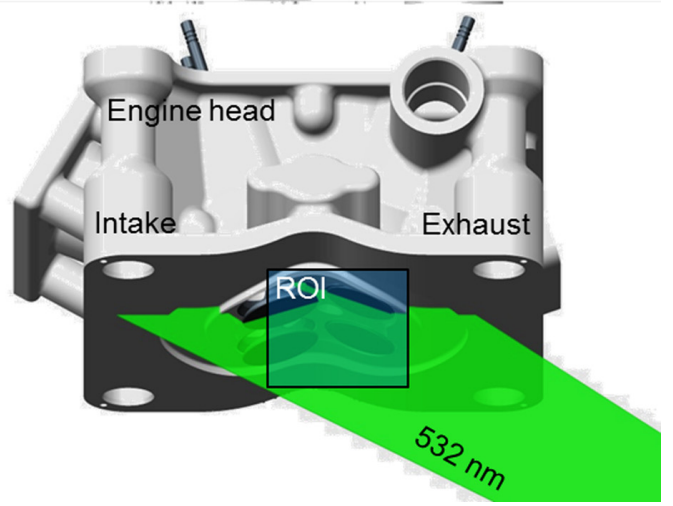

Figure 3

a) Side view and b) bottom view of engine head with ROI in the laser sheet.

Complete optical access to the valve gap is difficult. Figure 4 illustrates some of the issues. With the laser sheet arranged as shown in Figure 3b, a region above the valve disc is shadowed and scattered light cannot be detected in this area, marked red in Figure 4b. Thus, no experimental data is reported for this area.

Laser-light reflections were suppressed by black surfaces in the cylinder head and on the back of the measurement tube. A $532 \mathrm{~nm}$ band pass filter was mounted in front of the camera lens, suppressing ambient room light. The light scattered by the seed particles was detected through the acrylic cylinder by a CMOS camera (PCO Edge 5.5, $\left.2560 \times 2160 p x^{2}\right)$ digitized to 16 bit. A commercial camera lens with a focal length of $50 \mathrm{~mm}$ (Nikon AF-D) was combined with a close-up lens (Canon $52 \mathrm{~mm}, 500 D$ ) to yield a magnification of 0.29 . This projects an image section of $58 \mathrm{~mm} \times 48.9 \mathrm{~mm}$ onto the detector. The lens aperture was set to $f / 5$.6. PIV was performed with a repetition rate of $15 \mathrm{~Hz}$, which is much longer than the integral time scale of the intake flow. For the current work, 1200 image pairs from 12 data sets with 100 shots each were recorded. After 300 images the acrylic glass tube was cleaned to limit refractive

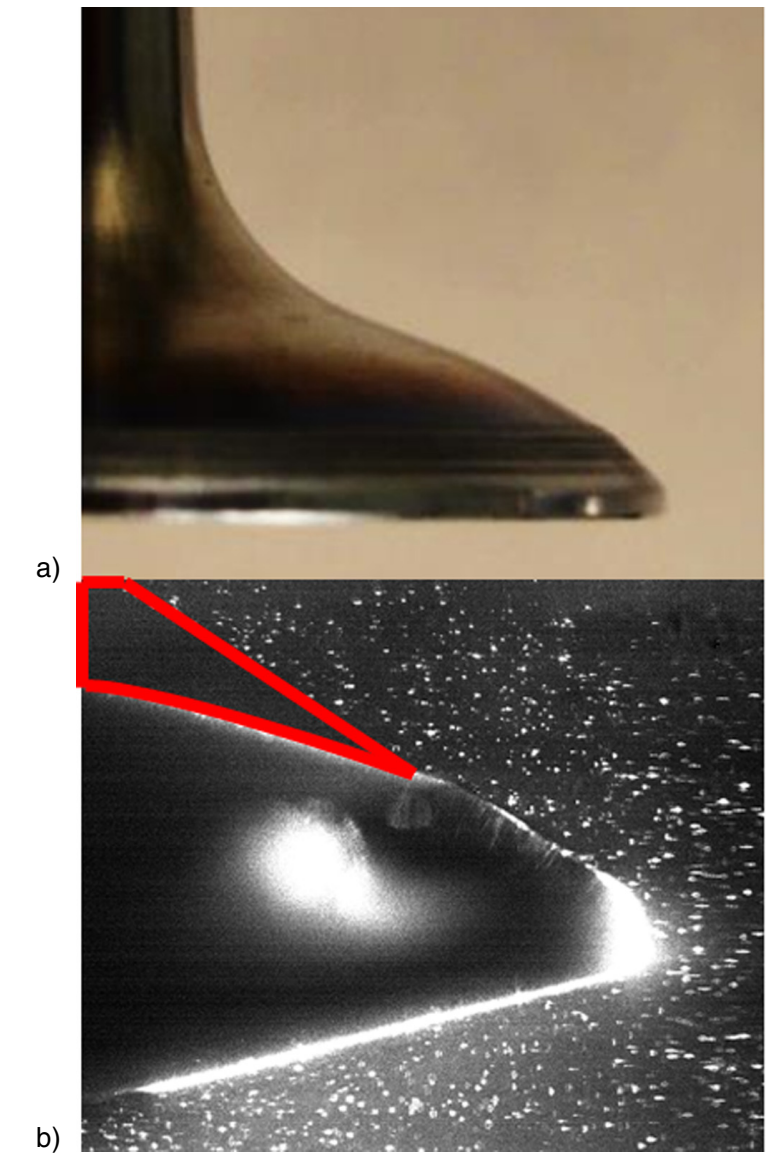

Figure 4

a) Intake valve and b) raw PIV data near the intake valve. The red triangle marks the region shadowed by the valve.

image distortion caused by the build-up of a liquid film of seed material on the inner surfaces. This effect leads to defocused particle images and a lower signal-to-background ratio. The apparent particle "size" (the area covered by scattering from a single particle on the sensor) and seeding density were also cross-checked by the imaging software, with the particle size estimated from the width of the auto-correlation peak of the pixels inside the ROI. To avoid peak locking effects resulting in inaccuracies in the velocity calculation, the lens aperture was set to achieve an apparent size of 2-4 pixels. Particle density was determined by means of simple thresholding segmentation with a signal threshold three times that of the background signal [17].

The image acquisition, scaling, and vector map computation were carried out using DaVis 8.1.4 (LaVision). Image distortion caused by the round measurement tube was corrected with a 3rd order polynomial fit based on a target placed in the field of view. The cross-correlation algorithm is described in Section 1.3. 
Figure 5 illustrates the ROI with a final spatial resolution of $725 \mu \mathrm{m}$. Figure 5a shows an example of PIV raw data with background light scattering due to laser reflections on the surfaces of the acrylic glass cylinder. The resulting vector field is shown in Figure 5b. The ROI was chosen to investigate in detail the instationary behavior of the intake jet flow (jet flapping), its penetration depth, and potential interactions between the jet and the cylinder wall. Figures $5 \mathrm{c}$ and $5 \mathrm{~d}$ show close-ups of the vector field. The jet break-up position and transition to turbulence are clearly visible. The high image resolution allows particles to be detected quite close to the valve. The detrimental effect of the shadowing illustrated in Figure 4 can be seen in Figure 5b. Additional limitations to flow measurements very close to the top of the valve disk, especially towards the valve stem, are imposed by seeding material collecting on the valve, thereby increasing reflections.

\subsection{PIV Evaluation Procedure}

\section{Software Settings in DaVis}

In the first step of processing the PIV image, the background light scatter is subtracted from the original PIV images. Next, objects that do not belong to the flow domain are masked out. Afterwards, the particle image intensity is normalized with a min/max-filter to obtain homogeneous particle intensities. The vector calculation is carried out with a cyclic FFT-based cross-correlation algorithm and multipasses with decreasing grid size and the "adaptive PIV" option [18]. This option automatically optimizes the interrogation window shape according to the local seeding density and flow gradients from the previous pass. The first passes are calculated with round Gaussian-weighted interrogation windows. In the first two passes, an interrogation window of $64 \times 64$ pixel $^{2}$ with an overlap of $50 \%$ is set. In the following two passes, the interrogation window size is set to $32 \times 32$ pixel $^{2}$ with an overlap of $75 \%$. Between each evaluation pass, a 4-pass regional median filter is applied, suppressing spurious vectors. Additionally, groups with less than 10 vectors are removed. Finally, a denoise filter (a fit with a polynomial of 2 nd order) with $3 \times 3$ kernel size is applied in order to remove high-frequency noise from the vector field. Rejected vector data are interpolated using the $M A T L A B$ function "inpaint-nans". At the chosen magnification, the interrogation window size of $32 \times 32$ pixel $^{2}$ corresponds to $725 \times 725 \mu^{2}$, and a $75 \%$ overlap yields $4 \times 4$ vectors in each of these interrogation windows.

\section{Quality and Reliability of the PIV Data}

The first quality criteria is the peak lock value, which error due to peak locking is negligible [17]. Another measure of

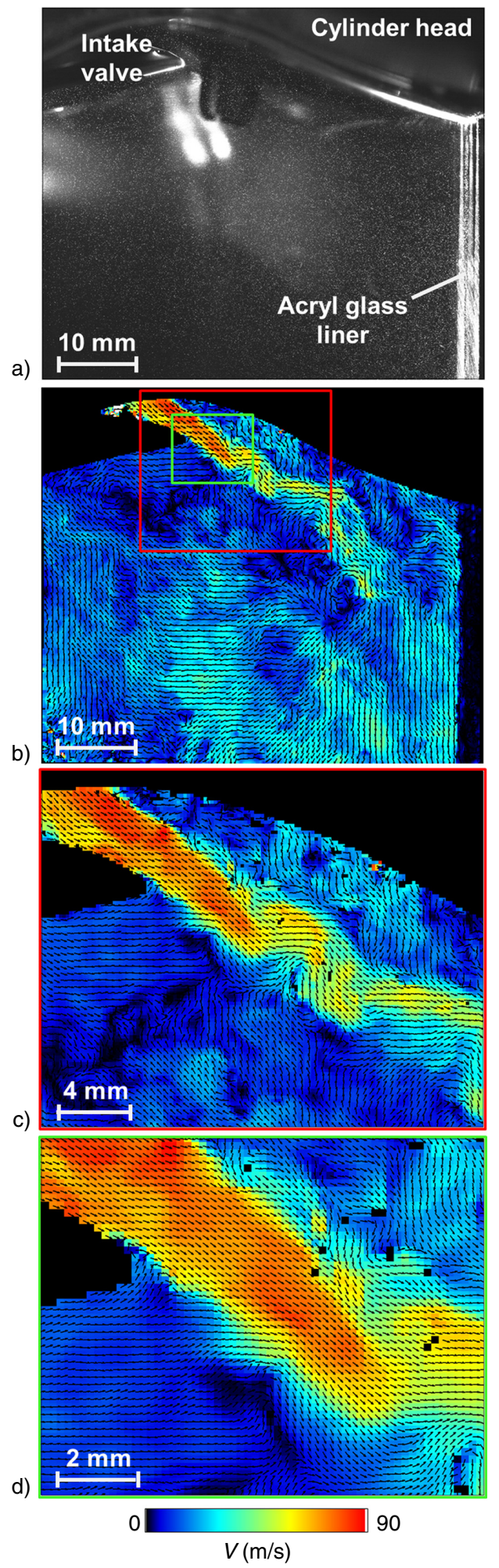

Figure 5

a) PIV raw image of the ROI in the center plane of the intake valve; b) velocity field determined from a single exposure in the ROI (every 4th vector is shown); c) and d) successively enlarged close-ups of this vector field, as indicated by the frames in b). 


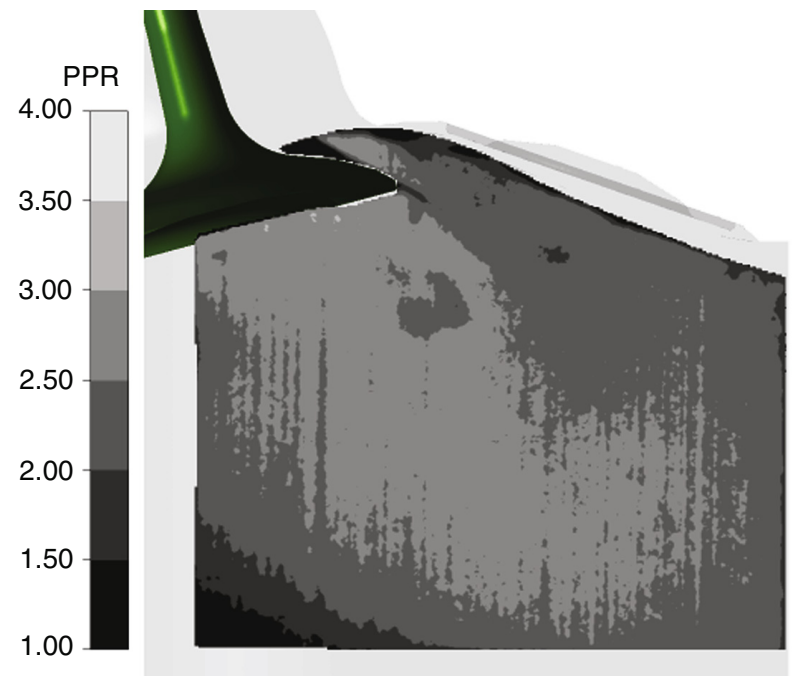

Figure 6

Mean PPR for 100 image pairs.

the quality of the PIV data is the Primary Peak Ratio (PPR), which is calculated according to [17] as:

$$
P P R=\frac{P_{1}-\min }{P_{2}-\min }
$$

with $P_{1}$ being the peak correlation value within the interogation window, $P_{2}$ the second-highest peak, and min the base value far from these peaks. It is a relative ratio that takes the background level into account and should be higher than 1 to ensure valid correlation peak detection. The mean PPR for 100 image pairs is illustrated in Figure 6.

The figure shows that the PPR is always larger than 1 except in the lower left corner, in the upper part of the valve gap, and in the shadowed region above the valve. This is caused by insufficient illumination and spurious vector data. However, in the remaining ROI, the PPR is larger than 2 and the total fraction of spurious vector data is below $5 \%$.

\section{SIMULATION}

\subsection{Numerical Method}

All simulations are performed using ANSYS CFX Release 15.0. This implicit and node-centered code solves the governing equations based on a finite volume approach.
For constant-density flows, the following Reynoldsfiltered equations for mass - Equation (2) - and momentum Equation (3) - have to be solved:

$$
\begin{gathered}
\frac{\partial \bar{u}_{i}}{\partial x_{i}}=0 \\
\rho\left(\frac{\partial \bar{u}_{i}}{\partial t}+\bar{u}_{j} \frac{\partial \bar{u}_{i}}{\partial x_{j}}\right)=-\frac{\partial \bar{p}}{\partial x_{i}}+\frac{\partial}{\partial x_{j}}\left(\tau_{i j}+\tau_{i j}^{m o d}\right)
\end{gathered}
$$

The quantity $\tau_{i j}^{m o d}$ requires an adequate turbulence model, which is described in Section 2.2.

The numerical discretization schemes for scale-resolving engine simulations were chosen as discussed in [19-22]. The time step was chosen such that the CourantFriedrichs-Lewy number (CFL), defined as:

$$
\mathrm{CFL}=\frac{\bar{u} \cdot \Delta t}{\Delta x}
$$

is smaller than unity.

\subsection{Turbulence Model}

A closure is required for $\tau_{i j}^{\text {mod }}$ in the momentum equations (Eq. 3). The stationary flow bench is a challenging test case for a scale-resolving simulation because of the combination of large velocity gradients in the jet region, the wall boundary layer in the valve gap and flow separation at the valve. A standard LES approach, e.g. using the Smagorinsky model, requires very high spatial, nearly isotropic resolution, especially in the boundary layer. Since the time-step has to be adjusted accordingly, the numerical cost increases significantly. To overcome this problem, the simulations were performed based on the Detached-Eddy Simulation (DES) approach developed by Travin et al. [23]. This model offers a good compromise between accuracy, resolution of turbulent fluctuations, and computational effort, because it combines a URANS and an LES formulation. It is based on the Shear Stress Transport (SST) turbulence model [24] and solves a transport equation for turbulent kinetic energy $k$ and turbulent frequency $\omega$. The turbulent dissipation in the $k$ equation of the SST model, written as:

$$
D_{k}^{S S T} \sim \rho k \omega \sim \rho \frac{k^{\frac{3}{2}}}{l_{t}}
$$

is replaced by:

$$
D_{k}^{D E S} \sim \rho \frac{k^{\frac{3}{2}}}{l_{D E S}} \text { with } l_{D E S}=\min \left(l_{t}, C_{D E S} \Delta\right)
$$




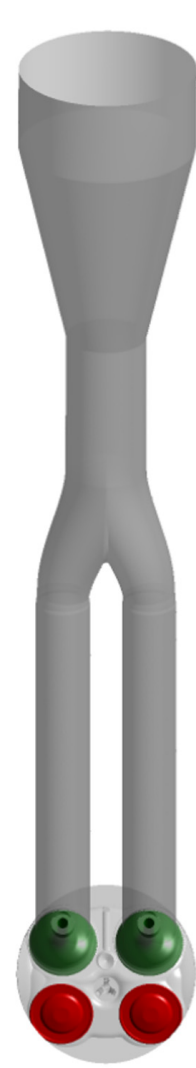

a)

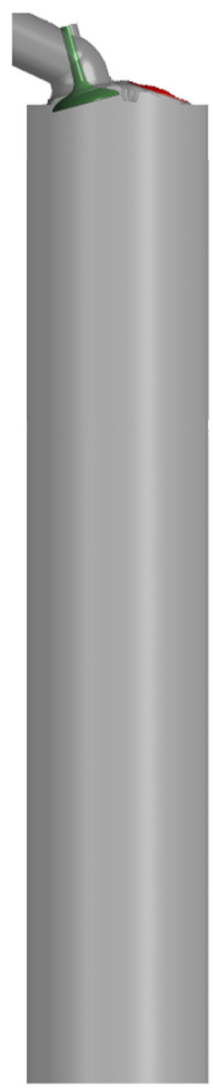

b)

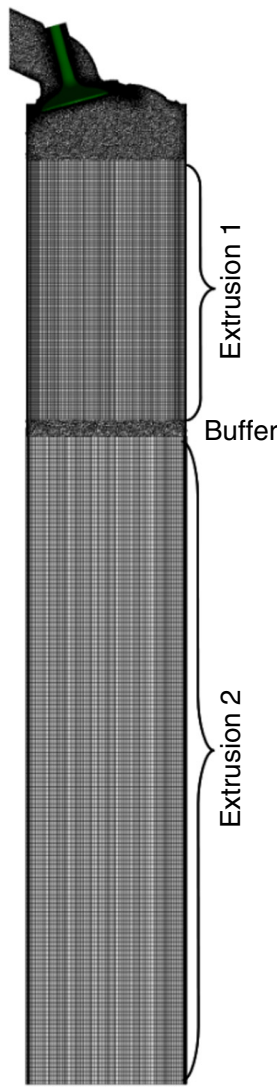

c)
Figure 7

a) Top view; b) side view of the simulation domain and c) numerical mesh with 20 million grid points.

which enables local switching from URANS to scale-resolving simulations. The capability of the turbulence model to resolve turbulent fluctuations is directly linked to the local filter size $\Delta$. For ANSYS CFX Menter and Kuntz [25] altered the pure grid-induced blending function and introduced an additional SST-based blending to overcome the problem of erroneously pressure-induced flow separation.

The DES-SST model guarantees at least URANS behavior in regions where grid resolution is not sufficient for LES. Here, such regions are found in particular close to the walls, where an order of magnitude more grid points would otherwise be required.

\subsection{Numerical Model}

Figure 7 shows the top view and the side view of the numerical domain for the flow bench test rig as well as the corresponding mesh for a valve lift of $5 \mathrm{~mm}$. The simulation's boundary conditions were extracted from the experiments,

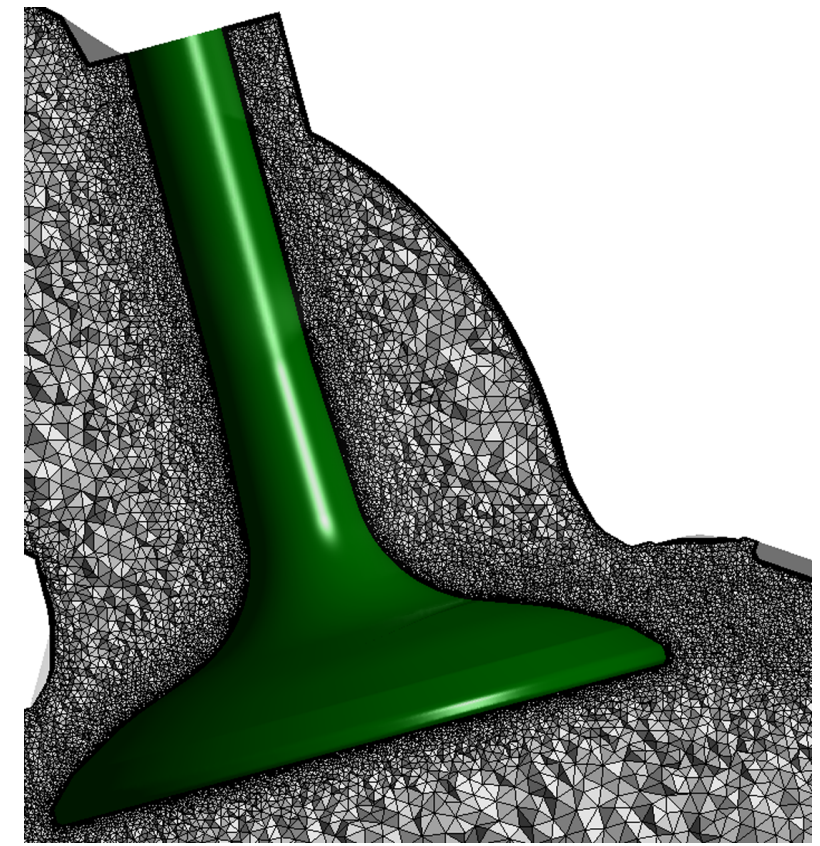

Figure 8

Detailed mesh view illustrating the volumetric refinement regions around the valve stem, in the valve gap and in the jet shear layers.

see Section 1. For a realistic velocity distribution and a fully developed boundary layer at the end of the intake pipe almost the entire intake port illustrated in Figure 2 was included in the simulation. A mass flow of $3 \mathrm{~kg} / \mathrm{min}$ was set at the inlet according to the experimental value and an outflow boundary condition with ambient pressure was used at the end of the cylinder tube.

Two different meshes, $\mathrm{M}_{1}$ and $\mathrm{M}_{2}$, are investigated in the following with a focus on the high resolution mesh $\mathrm{M}_{2}$. In both cases, the numerical domain is discretized using a hybrid mesh consisting of tetrahedral, hexahedral, and prism elements. In the upper part of the domain, which has a complex geometry, the mesh consists of tetrahedral elements with mesh refinements at the separation edge at the intake port, at the valve shaft, in the valve gap, and in the shear layer region of the intake jet (Fig. 8). Prism elements at the wall are used to resolve the boundary layer flow.

Based on this upper part, the cylinder volume was generated by extruding the surface mesh, and it consists of prism and hexahedral elements, which yields a reduced number of elements compared to a pure tetrahedral-prism grid. The extrusion mesh was split into two parts (Extrusion 1 and Extrusion 2; Fig. 7), which have lengths of 2 and 3 times the bore diameter, respectively. To avoid hanging nodes, a buffer volume with a tetrahedral-based transition zone is 
TABLE 1

Grid information and estimated time step requirements. BL: boundary layer

\begin{tabular}{c|c|c}
\hline Grid type & $\mathrm{M}_{1}$ & $\mathrm{M}_{2}$ \\
\hline Elements & $10 \times 10^{6}$ & $105 \times 10^{6}$ \\
\hline Nodes & $1.5 \times 10^{6}$ & $20 \times 10^{6}$ \\
\hline Domain volume & $3416 \mathrm{~cm}^{3}$ & $3416 \mathrm{~cm}^{3}$ \\
\hline$\Delta_{\max }$ & $2 \mathrm{~mm}$ & $2 \mathrm{~mm}$ \\
\hline$\Delta_{\min }$ & $0.5 \mathrm{~mm}$ & $0.25 \mathrm{~mm}$ \\
\hline BL resolution & $10 \mathrm{nodes}$ & $10 \mathrm{nodes}$ \\
\hline$u_{\max }$ & $80 \mathrm{~m} / \mathrm{s}$ & $80 \mathrm{~m} / \mathrm{s}$ \\
\hline$\Delta t$ & $6 \mu \mathrm{s}$ & $3 \mu \mathrm{s}$ \\
\hline$t_{\text {tot }}$ & $30 \mathrm{~s}$ & $3 \mathrm{~s}$ \\
\hline
\end{tabular}

placed between these two extrusion volumes. This methodology allows the maximum grid size to increase from $1 \mathrm{~mm}$ in the Extrusion 1 volume to $2 \mathrm{~mm}$ in the Extrusion 2 volume. To reduce numerical errors, a small cell growth ratio of about 1.1 is used over the entire domain. Overall, the larger mesh $\mathrm{M}_{2}$ consists of 105 million elements. Further mesh information is given in Table 1 .

The minimum cell width $\Delta_{\min }$ occurs in the volumetric refinement for the jet shear layer. This cell width, together with the maximum jet velocity and the CFL condition of unity, yields the time step $\Delta t$ in Table 1 . The total simulation time $t_{\text {tot }}$ is chosen to obtain sufficient statistical information on large-scale motions and to generate a sufficient number of snapshots which can be compared to the experimental results.

\section{RESULTS}

In this section, a comparison of the numerical and experimental results is presented and discussed. First, we consider the spatial resolution of the PIV measurements and compare it to the simulations, followed by comparisons of the instantaneous and mean flow fields. The "relevance index" and other statistical tools are used to evaluate the general agreement between simulation and two-dimensional, twocomponent PIV (2D-2C PIV) measurements. Additionally, an investigation of the boundary layer at the intake valve seat examines the flow separation and the accuracy of the standard wall-function formulation. Finally, large-scale structures induced by flow separation behind the valve stem will be examined using Fourier analysis in order to determine how far their influence reaches into the combustion chamber.

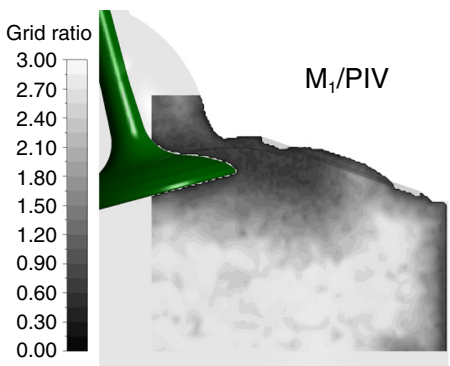

a)

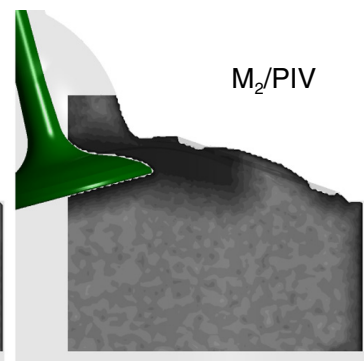

b)
Figure 9

Cell width ratio (grid ratio) of a) $\mathrm{M}_{1} / \mathrm{PIV}$ and b) $\mathrm{M}_{2} / \mathrm{PIV}$ illustrating the spatial resolution of the meshes for the simulation compared to that of the PIV.

\subsection{Comparison between Simulation and Experiment}

First, the spatial resolution of each simulation mesh is considered and compared to the PIV grid. The local cell size for $\mathrm{M}_{1}$ and $\mathrm{M}_{2}$ is approximated as the cubic root of the finite volumes. The equidistant cell width from PIV is restricted by the interrogation window size of $32 \times 32 \mathrm{pixel}^{2}$. The cell width divided by the equidistant cell width from PIV yields the GridRatio, which then reads

$$
\text { GridRatio }=\frac{V_{\text {Sim }}^{1 / 3}}{\Delta_{\mathrm{PIV}}}
$$

Figure 9 compares this ratio between the two different computational grids. A grid ratio of unity means that the grid spacing in the experiment $\Delta_{\text {PIV }}$ and the mean cell width in the simulation $V_{\text {Sim }}^{1 / 3}$ are identical. Values smaller than unity indicate higher resolution in the simulation and vice versa. Figure 9 shows locally refined areas for $\mathrm{M}_{1}$ as well as for $\mathrm{M}_{2}$ that are of similar shape, whereas $\mathrm{M}_{2}$ has much higher resolution in the combustion chamber and jet area corresponding to a smaller cell size (Tab. 1). The local refinement in the vicinity of the jet shear layer can be clearly identified. Here, the numerical grid has even higher resolution than the PIV. However, the resolution in regions far from shear layers is not as good as in the PIV.

While the grid ratio in Figure 9 was based on the size of the PIV interrogation area, further evaluation of the experiment will use all $4 \times 4$ vectors calculated in each interrogation area. A qualitative impression of the spatial resolution of the velocity field of the simulation and the experiment is given in Figure 10. 2D-2C PIV measurements provide the two velocity components $(u, v)$ only. Accordingly, the instantaneous resolved velocity magnitude:

$$
\operatorname{vel}_{\text {mag }}=\sqrt{\vec{u}^{2}+\vec{v}^{2}}
$$




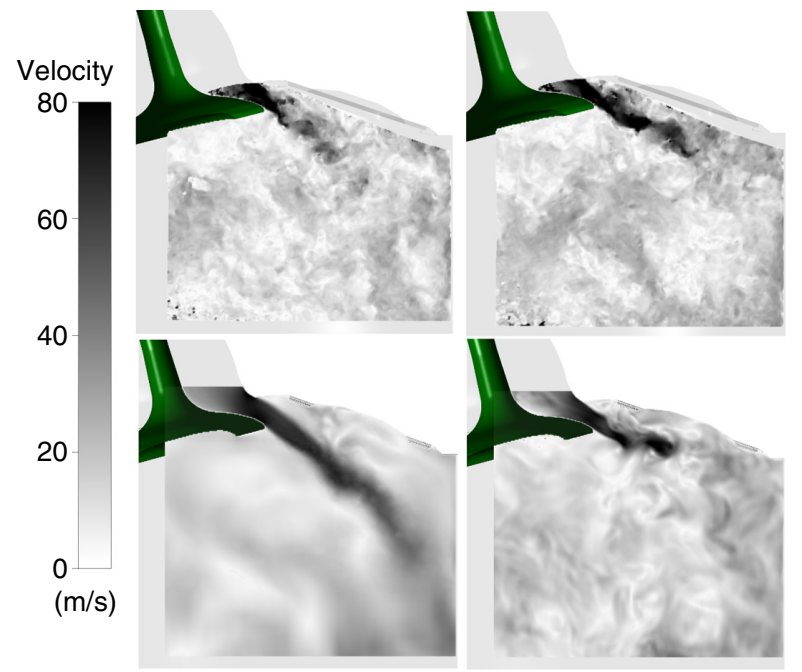

Figure 10

Velocity magnitude: two time steps from PIV (top) and a single simulation time step on mesh $\mathrm{M}_{1}$ (left, bottom) and $\mathrm{M}_{2}$ (right bottom).

and the time-averaged resolved velocity magnitude:

$$
\left\langle\operatorname{vel}_{\text {mag }}\right\rangle=\sqrt{\left\langle\bar{u}^{2}\right\rangle+\left\langle\bar{v}^{2}\right\rangle}
$$

from the simulations is based also on two velocity components only.

As expected, PIV shows more small-scale structures compared to the simulation on both simulation meshes. The flow field on mesh $\mathrm{M}_{1}$ shows the least resolved turbulent scales. The result of mesh $\mathrm{M}_{2}$ shows significantly more fluctuations, compared to mesh $\mathrm{M}_{1}$. For mesh $\mathrm{M}_{2}$, the spatial resolution is sufficiently fine to resolve large-scale fluctuations.

An approximation for the quality of scale-resolving simulations is the ratio of the resolved to the total turbulent kinetic energy $k_{\text {res }} / k_{\text {tot }}$. Pope [26] proposed that an LES should resolve at least $80 \%$ of the Turbulent Kinetic Energy (TKE). However, this criterion might not be suitable for very coarse grids. In view of the relatively fine mesh, we adopt Pope's criterion here. Further, analysis of grid quality indicators for scale-resolving simulations can be found in Celik et al. [27] and Kempf et al. [28].

The total TKE energy is calculated by:

$$
k_{\text {tot }}=k_{\text {res }}+k_{\text {sgs }}
$$

While the calculation of the kinetic energy of the resolved fluctuations $u_{i}^{\prime}=\bar{u}_{i}-\left\langle\bar{u}_{i}\right\rangle$ is straightforward:

$$
k_{\text {res }}=\frac{1}{2}\left(u_{i}^{\prime} u_{i}^{\prime}\right)
$$

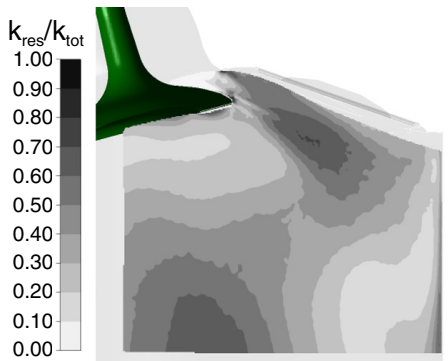

a)

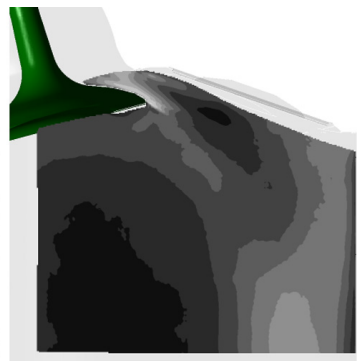

b)

\section{Figure 11}

Time-averaged ratio of resolved and total TKE on meshes a) $M_{1}$ and b) $M_{2}$.

the modeled velocity fluctuations have to be estimated based on the eddy viscosity $v_{t}$ and the turbulent dissipation rate $\varepsilon$ :

$$
v_{t}=C_{M} \frac{k_{\mathrm{sgs}}^{2}}{\varepsilon}
$$

The turbulent dissipation can be approximated using the resolved shear strain $S_{i j}$ and the turbulent viscosity [29] and reads:

$$
\varepsilon=2 v_{t} S_{i j} S_{i j}
$$

Finally, the modeled TKE can be approximated as:

$$
k_{s g s}=\left(\frac{2 v_{t}^{2} S_{i j} S_{i j}}{C_{M}}\right)^{0.5}
$$

Based on the underlying SST turbulence model, the constant $C_{M}$ is set to 0.09 .

Figure 11 shows the locally estimated ratio of resolved to total for meshes $M_{1}$ and $M_{2}$ averaged over all snapshots. As expected, mesh $M_{1}$ shows significantly lower resolution compared to mesh $\mathrm{M}_{2}$ in terms of velocity fluctuations, while neither $\mathrm{M}_{1}$ nor $\mathrm{M}_{2}$ resolve the entire section investigated here with a ratio greater than $80 \%$. In particular, close to the intake valve, the ratio in both simulations is very small, which indicates insufficient resolution. In contrast, the modeled velocity fluctuations in the combustion chamber are low, due to low velocity gradients, which yields TKE ratios close to unity.

Figure 12 shows the time-averaged velocity magnitude (Eq. 8) and velocity fluctuation of the resolved flow field for the simulation on mesh $\mathrm{M}_{2}$ compared to PIV. The lines $L_{1}$ and $J L$ will be consider below in further investigation of velocity magnitude, velocity fluctuation, and jet orientation. The two-dimensional resolved fluctuating 

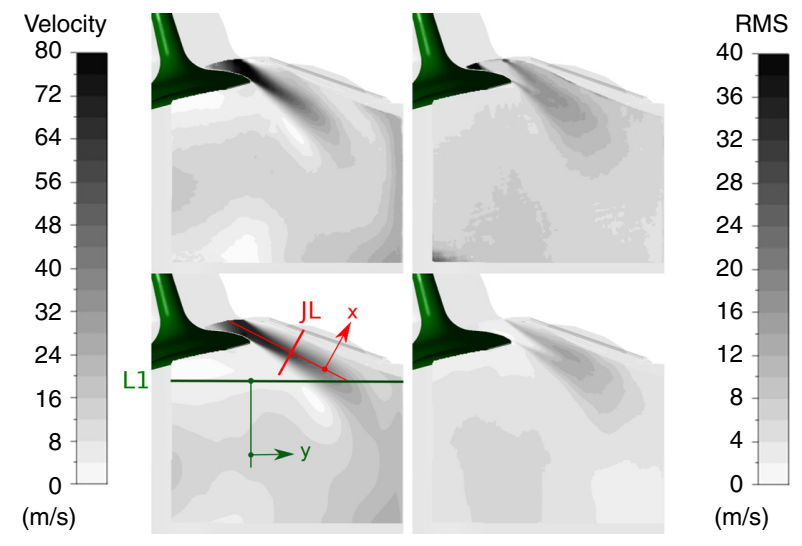

Figure 12

Time-averaged velocity magnitude (left) and RMS velocity (right) from PIV (top) and simulation (bottom) on mesh $\mathrm{M}_{2}$.

velocity magnitude in simulation and PIV are quantified by Equation (15):

$$
u_{r m s}=\sqrt{\frac{1}{2}\left(\left\langle u^{\prime} u^{\prime}\right\rangle+\left\langle v^{\prime} v^{\prime}\right\rangle\right)}
$$

Comparing the velocity magnitude from the simulation (Fig. 12, bottom) and experiment (Fig. 12, top), all characteristics of the mean flow field from the experiment can be found in the simulation. Since the jet is the dominating flow structure in this case, its orientation is important. Figure 12 shows that the simulated jet is slightly tilted upwards towards the cylinder head compared to the PIV experiment. One explanation is the manufacturing tolerance of the valve seat, which has a well-defined edge according to the CFD model, while the real edge has a finite radius. That means the point of flow separation might be slightly shifted, which influences the mean orientation of the jet. Nevertheless, with respect to the velocity magnitude and resolved velocity fluctuations, in general we find good agreement between simulation and experiment. Concerning the fluctuations, the PIV experiment shows areas of high Root Mean Square (RMS) close to the valve stem and in the bottom left corner of the ROI. In these areas, the primary peak ratio in the PIV is low, indicating that vector noise may contribute significantly to the RMS. In contrast, the high values of RMS velocity close to the valve jet are characteristic of turbulent jets. These high-RMS-zones may also partially be due to the jet "flapping" up and down. This non-stationary character of the jet can be identified in both PIV image series as well as in the time-resolved simulation.

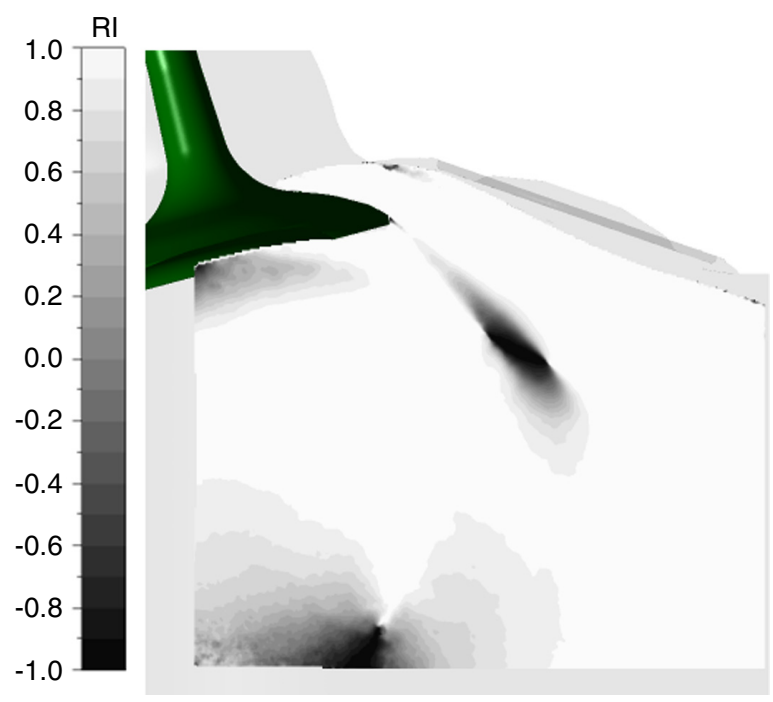

Figure 13

RI between the time-averaged velocity fields from simulation and PIV measurements.

In addition to the magnitudes, the orientation of the velocity vectors can be investigated by the Relevance Index (RI), defined as:

$$
R I=\frac{\vec{u} \cdot \vec{v}}{\|\vec{u}\|\|\vec{v}\|}
$$

This index was introduced by Liu and Haworth [30] and it is well suited for finding correlations between different flow fields. It compares vector orientations by projecting the velocity vectors of a flow field $\vec{u}$ onto the velocity vectors of another flow field $\vec{v}$. The range of RI lies between -1 (parallel, opposite direction) and 1 (parallel, same direction). A value of zero means that the vectors are orthogonal. The vector $\vec{u}$ is represented by the two time-averaged velocity components of the PIV and the vector $\vec{v}$ is represented by the corresponding two time-averaged velocity components of the simulation.

Figure 13 shows the local deviations in orientation between the experiment and the simulation using the RI. Averaged over the ROI, the RI is 0.85 . Regarding the local RI, the largest deviations are found in the lower jet shear layer. There, the penetrating jet establishes a local recirculation area. Since the downward inclination of the jet differs between the experiment and the simulation, the recirculation areas from the simulation and the jet from the experiment overlap in the area with a relevance index of -1 . The low $\mathrm{RI}$ in the bottom left corner of the section again is an indicator of uncertainties in the PIV measurements, caused by insufficient illumination, as discussed in Section 1.3. 

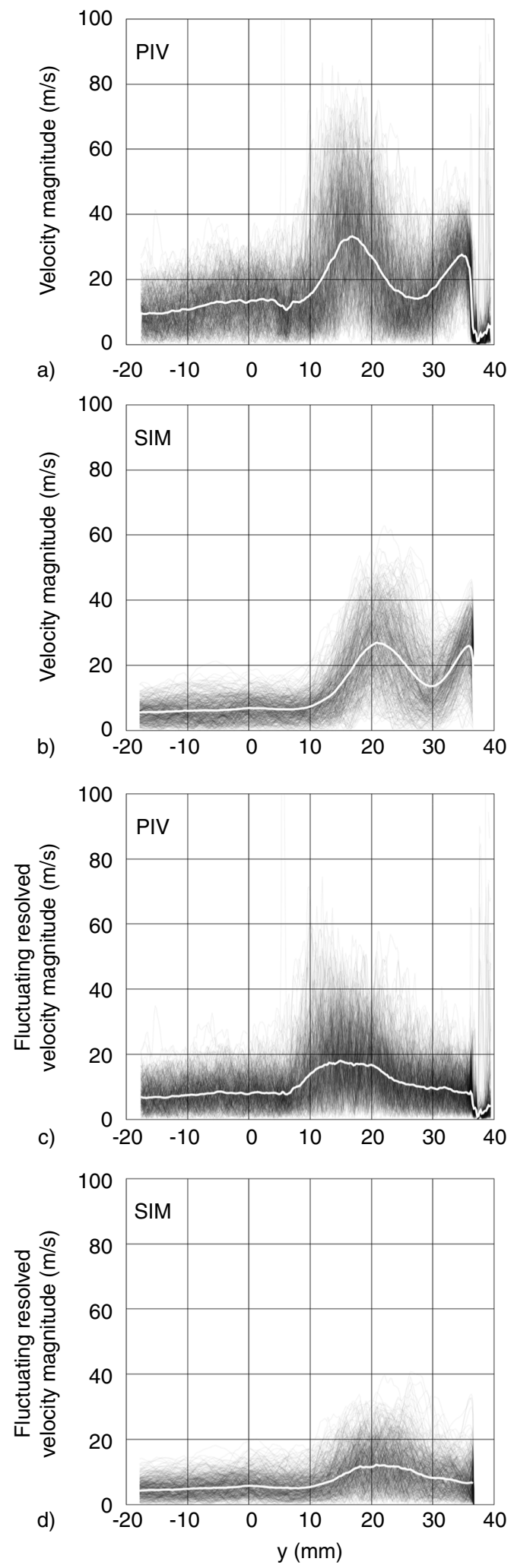

Figure 14

Velocity magnitude from simulation a) and experiment b) at line $L_{1} ;$ c) and d) show the fluctuating velocity from experiment and simulation. The white line represents the time-average, while the black lines are from individual snap-shots.

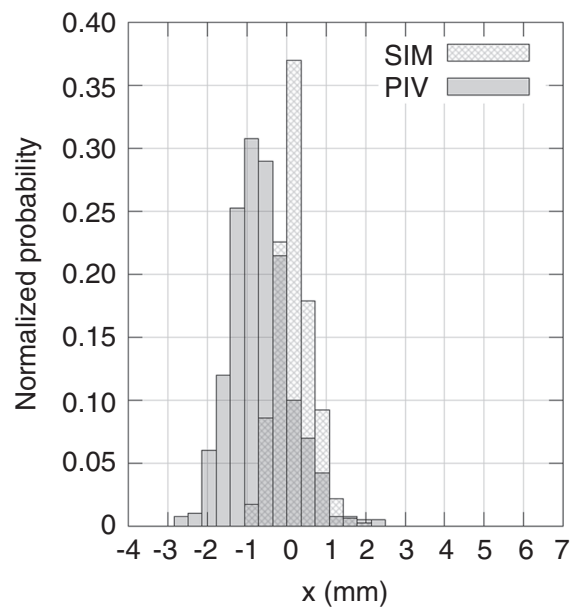

Figure 15

Probability of the jet-centerline being located at some value $x$ along line $J L$, accumulated over the ensemble of snap-shots.

A more detailed analysis is presented in Figure 14 based on the velocity magnitude and fluctuating velocity at line $L_{1}$. Figure 14 plots values from the individual snap-shots in black, while the white line represents the time-average. Comparing the time-averaged velocities between the simulation and the experiment, the peak velocities and the velocities near the jet are in good agreement, but the location of the maximum velocities is different. The maximum velocity is located at $y=22 \mathrm{~mm}$ in the simulation and $y=17 \mathrm{~mm}$ in the PIV. As discussed in the previous section, the deviation of the jet orientation between experiment and simulation influences the entire flow field. Because of that, the locations of the peak velocities and the shape of the velocity profile are different. For example, at $y=5 \mathrm{~mm}$, the simulations show the velocity magnitude slightly increasing to higher $y$-coordinate, while the PIV result shows a sharp local minimum. The time-averaged velocity fluctuations from the simulation is similarly shifted to a higher $y$-value with respect to the PIV results. In both simulation and experiment, the snapshots have large scatter, highlighting again the strongly fluctuating character of the flow. The maximum velocity magnitude values are about $50 \mathrm{~m} / \mathrm{s}$ and $70 \mathrm{~m} / \mathrm{s}$ for the simulation and the experiment, respectively. Although a rigorous comparison is not possible with the number of snapshots depicted here, the scatter of the velocity fluctuations in the PIV exceeds that in the simulation by about a factor of two.

An analysis at line $J L$ provides some more detail on the deviation in jet orientation between simulation and experiment. Figure 15 presents the probability of the jet centerline 
being located at some value $x$ along line $J L$, accumulated over the ensemble of snapshots. To calculate this probability, in each snapshot the instantaneous velocity magnitude sampled along line $J L$ was thresholded at $95 \%$ of its maximum value. The jet centerline was then determined by averaging the $x$-values of the samples above the threshold. Line $J L$ is orthogonal to the intake-valve seat, with the origin of the coordinate $x$ being located at the intersection between $J L$ and a second line, which is parallel to the valve seat with a distance of $2.5 \mathrm{~mm}$ (half valve lift) from the valve seat (Fig. 12). Positive values of $x$ are towards the cylinder head and negative values towards the combustion chamber. The highest probability of finding the jet centerline can be found at $x=-1 \mathrm{~mm}$ for PIV and $x=0 \mathrm{~mm}$ for the simulation, i.e., a shift of the jet of about $1 \mathrm{~mm}$. Additionally, the range of jet fluctuations is higher in the PIV compared to the simulation. This illustrates that the jet is more "stable" in the simulation, another indicator that the resolution should be increased.

\subsection{Boundary Layer Profiles Upstream of the Intake Valve Seat}

The following section analyses the time-averaged boundary layer profiles upstream of the flow separation and specifically looks at the general agreement with the standard wall function. Here, the flow separation at the intake valve is geometrically fixed at the intake valve lip, which is marked by a yellow line in Figure 16. Following Schlichting et al. [31], the standard wall boundary layer can be classified into three zones. A viscous-sublayer is given for $y^{+}<5$, while the Log-Law is taken to be valid for $y^{+}>70$. The transition zone lies in between and neither the viscous-sublayer nor the Log-Law formulation is valid.

Figure 16 shows the non-dimensional boundary layer along the lines $L_{3}, L_{4}, L_{9}, L_{10}, L_{15}, L_{16}$ and the analytical formulation for the viscous sublayer and for the Log-Law region. The first line pair $\left(L_{15}\right.$ and $\left.L_{16}\right)$ is located upstream of the valve seat. The second line pair $\left(L_{3}\right.$ and $\left.L_{4}\right)$ is located at the smallest gap between intake port and intake valve. The lines $L_{9}$ and $L_{10}$ are located at the valve seat. The distances between each line pair are identical.

All of the simulated boundary layer profiles reach into the viscous sublayer. The boundary layer profiles at $L_{3}, L_{4}, L_{15}$ and $L_{16}$ match pair-wise, while the lines $L_{9}$ and $L_{10}$ show distinctively different results. This shows that the velocity profile upstream of the valve seat is fully developed, while the lines downstream of the valve seat do not have a fully developed profile, potentially because of the upstream edge of the valve seat. At none of the cross-sections are the simulated boundary layer profiles in good agreement with the analytical formulation. Similar numerical investigations by Jainski et al. [32] concentrate on the area around the cylinder head
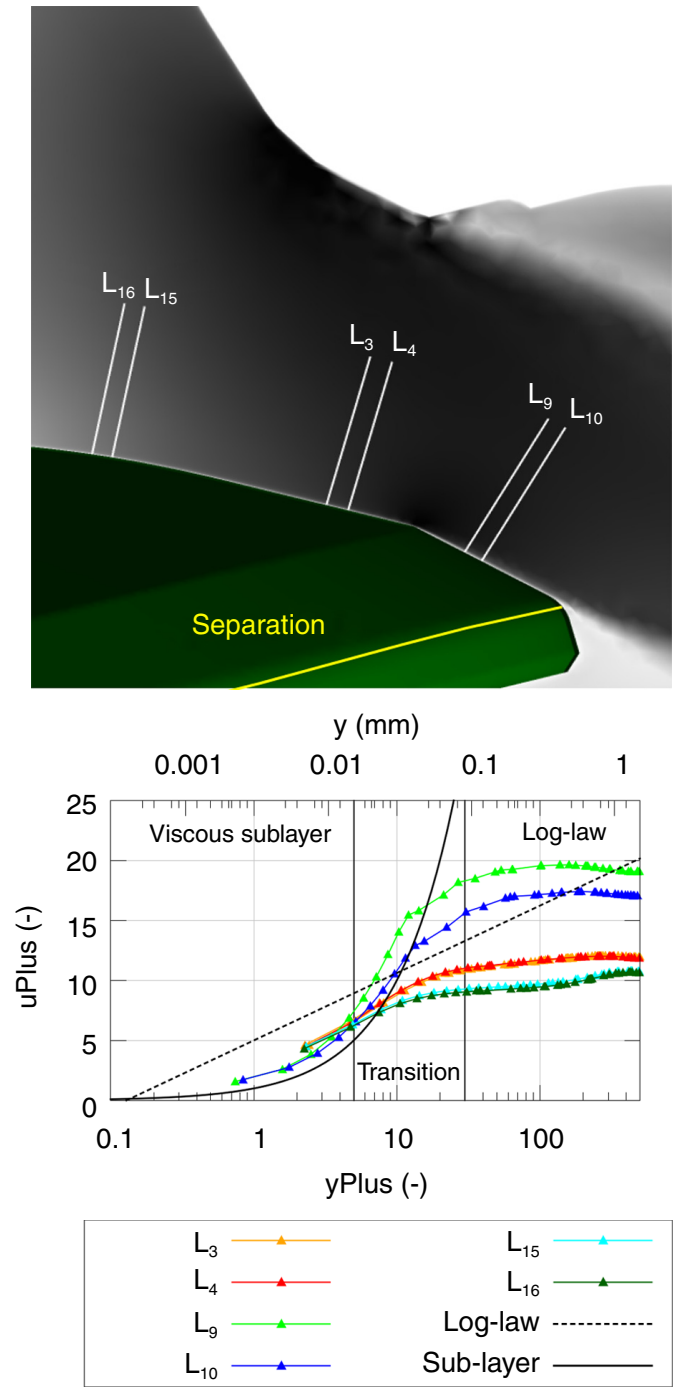

Figure 16

Dimensionless boundary layer profile above the intake valve including the analytical formulation for a fully turbulent flatplate boundary layer (bottom) and the lines of investigation upstream of the flow separation (top). The second $x$-axis of the plot presents the wall distance in $\mathrm{mm}$.

of an operating engine at various crank angles and confirm the potential inaccuracies when using the logarithmic wall functions.

\subsection{Frequency Analysis in the Vicinity of the Intake Valve Stem}

The vicinity of the intake valve is illustrated in Figure 17. Additionally, the points of interest for a detailed frequency analysis are presented. A recirculation area with vortexshedding develops in the wake. Based on these observations, 


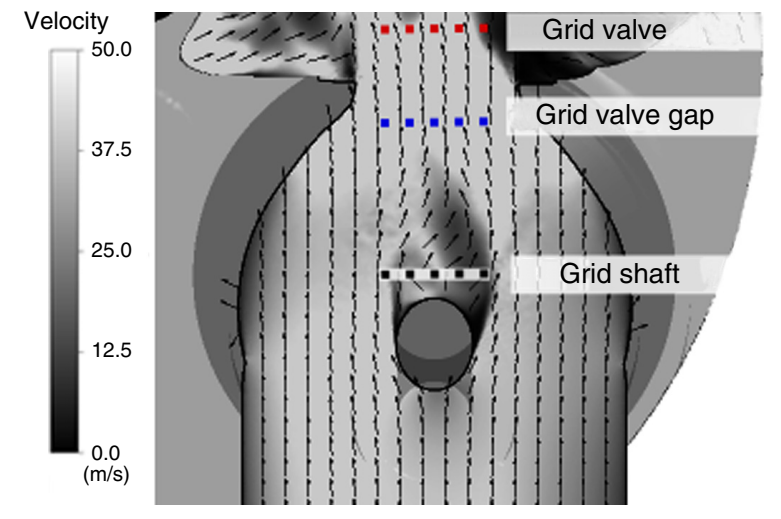

Figure 17

Snap-shot of the flow field around intake valve stem on a plane at the intake-pipe center line.

further analysis to identify dominant flow separation frequencies in the wake of the intake valve stem is carried out. We first calculate the Strouhal number, which with the frequency $f$, the characteristic diameter $d_{\mathrm{ch}}$ and the velocity $u_{\infty}$ is defined as:

$$
S r=\frac{f d_{\mathrm{ch}}}{u_{\infty}}
$$

The characteristic diameter $\left(d_{\mathrm{ch}}\right)$ is taken to be the hydraulic diameter for the elliptical cross-section $\left(d_{h}=4 A / U=3.53 \mathrm{~mm}\right)$ of the valve stem in the cut plane presented in Figure 17. The velocity $u_{\infty}$ is taken to be $45 \mathrm{~m} / \mathrm{s}$, which is the time-averaged velocity magnitude on the intake pipe centerline upstream of the valve stem. The Strouhal number of a flow past a cylinder was determined experimentally by Roshko [33]. In their work, the Strouhal number is plotted as a function of the Reynolds number $\left(R e=d_{\mathrm{ch}} u_{\infty} / v\right)$. Here, the Reynolds number based on the intake valve stem is 8680 , calculated using the hydraulic diameter of the ellipse and the molecular viscosity of air $\left(1.83 \times 10^{-5} \mathrm{~m}^{2} / \mathrm{s}\right)$. This yields a Strouhal number of 0.196 , which corresponds to a frequency of about $2500 \mathrm{~Hz}$.

To investigate the dominant frequencies of the velocity field behind the valve stem, we use a discrete Fourier transformation. If a dominant frequency can be identified, the question is whether it can "survive" the acceleration in the valve gap and thus can be a potential source of fluctuations in the jet. Probe points are placed within the numerical domain as illustrated in Figures 17 and 18. At each point and each time-step, all three velocity components are captured at three locations. The first one, Grid Shaft (GS), is placed directly behind the valve stem. The second one, Grid Valve Gap (GVG), is located within the valve gap.

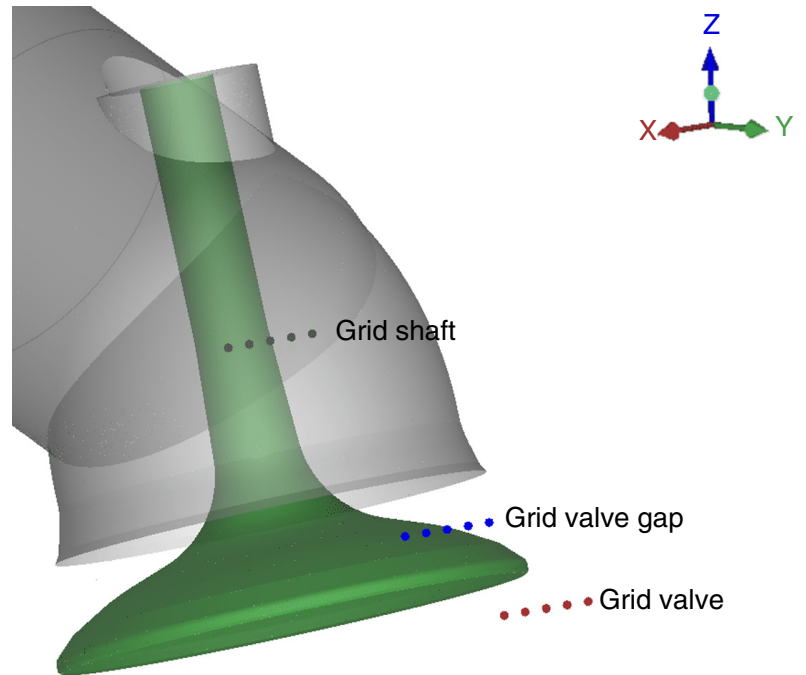

Figure 18

Locations of investigation Grid Shaft, Grid Valve Gap and Grid Valve within the flow bench geometry. The points along the $x$-axis show the locations for the detailed frequency analysis.

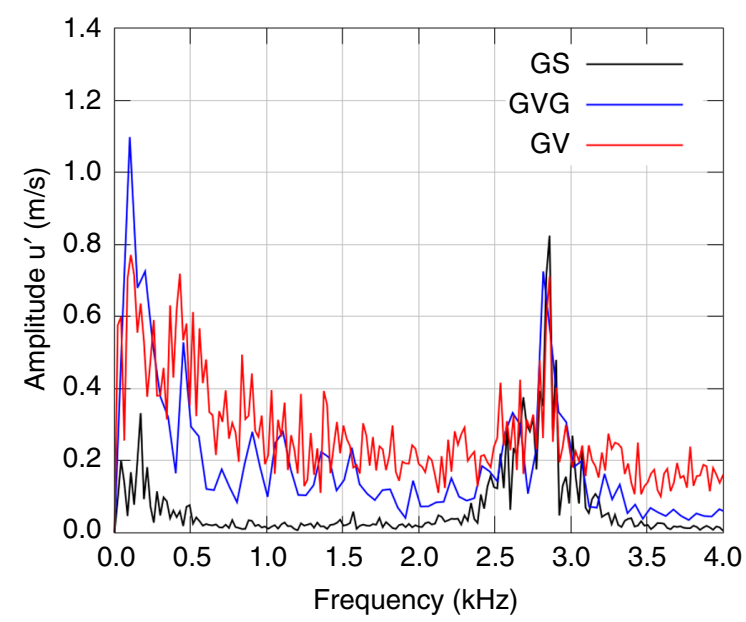

Figure 19

Fourier-transformed time series of the velocity fluctuation $u^{\prime}$ of all locations (Fig. 18).

The third one, Grid Valve (GV), lies downstream of the valve lip in the combustion chamber in the free-jet region.

First, all sampled data at the illustrated locations are timeaveraged to calculate the mean velocity. Subtracting the resulting mean velocity from instantaneous resolved velocity yields the resolved fluctuation. Averaging the velocity fluctuation along the points at GS, GVG and GV at each sampled time step yields a time series, which is used for the Fourier 
analysis. The Fourier analysis of each velocity component shows that indeed there is a dominant frequency in the fluctuating velocity component $u^{\prime}$ in $x$-direction. The amplitudes of the velocity fluctuations $u^{\prime}$ are presented in Figure 19 .

The location GS shows a significant fluctuation peak at $2860 \mathrm{~Hz}$, which corresponds approximately to that calculated from the Strouhal number. The locations GVG and GV show a broader range of relevant frequencies, but a distinctive peak at $2860 \mathrm{~Hz}$ can still be detected. The importance of other frequencies increase with increasing distance from the valve stem. Overall, the analysis indicates that the vortex structure behind the valve stem survives the acceleration through the valve gap into the combustion chamber.

\section{SUMMARY}

This work investigated the unsteady flow through the intake valve of a typical spark-ignited engine's cylinder head and how it influences the jet entering the combustion chamber. With the cylinder head on a flow bench, the valve lift was fixed at $5 \mathrm{~mm}$. The study utilized two-dimensional, twocomponent highly-resolved PIV and scale-resolving simulations on two different grids. Instantaneous flow fields illustrate the high resolution of the experimental data and locally even finer structures could be resolved than in the simulations on the finest grid. Generally, good agreement between the numerical and experimental velocity fields was observed. Statistical analysis of field-wide quantities as well as more detailed examination along selected line cuts through the data reveal some differences between experiment and simulation, in particular, in the orientation of the intake jet. Based on this, we suggest that even higher resolutions for the CFD simulation close to the jet should be the scope of future studies.

An analysis of the boundary layer profiles above the valve in the vicinity of the separation point revealed that the commonly-used wall formulation for $y^{+}>70$ was not applicable and the simulation grid should be fine enough to place the first grid point in the viscous sublayer as it is done here.

Finally, we investigated the vortex shedding at the valve stem. A Fourier analysis to identify dominant frequencies and a Strouhal-number-based approximation were compared. The Fourier analysis identified a dominant frequency at $2860 \mathrm{~Hz}$ in the wake of the stem, which is close to the Strouhal approximation of $2500 \mathrm{~Hz}$. This frequency was also found in the fluctuating velocity in the combustion chamber, downstream of the acceleration between the valve and its seat. This indicates that such vortices generated upstream of the valve gap can influence the flow field as far downstream as the combustion chamber and thus in an operating engine could be a potential trigger of cyclic variations.

\section{ACKNOWLEDGMENTS}

The authors kindly acknowledge the financial support by the Saxon Ministry of Science and Fine Arts, the SAB and the European Union in the project „DynMo” (project number 100113147), the Forschungsvereinigung Verbrennungsmotoren (FVV) and the Deutsche Forschungsgemeinschaft (DFG) in the project "BSZ II" (FVV project number 6011333, DFG project ID Schu 1369/11-2) and the Rückkehrerprogramm of the NRW Ministry for Innovation, Science, and Research. The simulations were performed on the national supercomputer Cray XC40 (Hornet) at the High Performance Computing Center Stuttgart (HLRS) under the grant number ICECCV/44054.

\section{REFERENCES}

1 Bicen A.F., Vafidis C., Whitelaw J.H. (1985) Steady and unsteady airflow through the intake valve of reciprocating engine, Journal of Fluids Engineering, Transactions of the ASME 107, 3, 413-420.

2 Heywood J.B. (1988) Internal combustion engine fundamentals, Mcgraw-Hill, New York.

3 Imberdis O., Hartmann M., Bensler H., Kapitza L., Thevenin D. (2007) A numerical and experimental investigation of a DISI-engine intake port generated turbulent flow, $S A E$ Technical Paper 2007-01-4047.

4 Stansfield P., Wigley G., Justham T., Catto J., Pitcher G. (2007) PIV analysis of in-cylinder flow structures over a range of realistic engine speeds, Experiments in Fluids 43, 1, $135-146$.

5 Namazian M., Hansen S., Lyford-Pike E., Sanchez-Barsse J., Heywood J., Rife J. (1980) Schlieren visualization of the flow and density fields in the cylinder of a spark-ignition engine, SAE Technical Paper 800044.

6 Weclas M., Melling A., Durst F. (1995) Unsteady intake valve gap flows, SAE Technical Paper 952477.

7 Weclas M., Melling A., Durst F. (1998) Flow separation in the inlet valve gap of piston engines, Progress in Energy and Combustion Science 24, 3, 165-195.

8 Valentino G., Kaufman D., Farrell P. (1993) Intake valve flow measurements using PIV, SAE Technical Paper 932700.

9 Bücker I., Karhoff D.C., Klaas M., Schröder W. (2012) Stereoscopic multi-planar PIV measurements of in-cylinder tumbling flow, Experiments in Fluids 53, 6, 1993-2009.

10 Baum E., Peterson B., Surmann C., Michaelis D., Böhm B., Dreizler A. (2013) Investigation of the 3D flow field in an IC engine using tomographic PIV, Proceedings of the Combustion Institute 34, 2, 2903-2910.

11 Freudenhammer D., Baum E., Peterson B., Böhm B., Jung B., Grundmann S. (2014) Volumetric intake flow measurements of an IC engine using magnetic resonance velocimetry, Experiments in Fluids 55, 5.

12 McLandress A., Emerson R., McDowell P., Rutland C. (1996) Intake and in-cylinder flow modeling characterization of mixing and comparison with flow bench results, SAE Technical Paper 960635. 
13 Inagaki M., Nagaoka M., Horinouchi N., Suga K. (2010) Large eddy simulation analysis of engine steady intake flows using a mixed-time-scale subgrid-scale model, International Journal of Engine Research 11, 3, 229-241.

14 Kaiser S.A., Schild M., Schulz C. (2013) Thermal stratification in an internal combustion engine due to wall heat transfer measured by laser-induced fluorescence, Proceedings of the Combustion Institute 34, 2, 2911-2919.

15 Gessenhardt C. (2013) Endoskopische Bestimmung des Temperaturfeldes im Brennraum von Ottomotoren mittels laserinduzierter Fluoreszenz, $P h D$ Thesis, Universität Duisburg-Essen.

16 Melling A. (1997) Tracer particles and seeding for particle image velocimetry, Measurement Science and Technology $\mathbf{8}$, $12,1406-416$.

17 LaVision (2013) Product-Manual Flow Master for DaVis 8.1.

18 Wieneke B., Pfeiffer K. (2010) Adaptive PIV with variable interrogation window size and shape, 15th International Symposium on Applications of Laser Techniques to Fluid Mechanics.

19 Hasse C., Sohm V., Durst B. (2009) Detached eddy simulation of cyclic large scale fluctuations in a simplified engine setup, International Journal of Heat and Fluid Flow 30, 1, 32-43.

20 Hasse C., Sohm V., Wetzel M., Durst B. (2009) Hybrid URANS/LES turbulence simulation of vortex shedding behind a triangular flameholder, Flow, Turbulence and Combustion 83, $1,1-20$

21 Hasse C., Sohm V., Durst B. (2010) Numerical investigation of cyclic variations in gasoline engines using a hybrid URANS/ LES modeling approach, Computers and Fluids 39, 1, 25-48.

22 Sohm V. (2007) Hybrid turbulence simulation to predict cyclic variations in internal combustion engines, $P h D$ Thesis, RWTH Aachen.

23 Travin A., Shur M., Strelets M., Spalart P.R. (2004) Physical and numerical upgrades in the detached-eddy simulation of complex turbulent flows, Fluid Mechanics and its Applications 65, 239-254.
24 Menter F.R. (1994) Two-equation eddy-viscosity turbulence models for engineering applications, AIAA journal 32, 8, 1598-1605.

25 Menter F.R., Kuntz M. (2003) Development and application of a zonal DES turbulence model for CFX-5, ANYSYS CFX validation report, Technical report, ANSYS.

26 Pope S.B. (2000) Turbulent Flows, Cornell University, 1st ed,

27 Celik I., Klein M., Janicka J. (2009) Assessment measures for engineering LES applications, Journal of Fluids Engineering 131, 3, 031102.

28 Kempf A., Geurts B., Ma T., Pettit M., Stein O. (2011) Quality issues in combustion LES, Journal of Scientific Computing 49, $1,51-64$

29 Tennekes H., Lumley J.L. (1972) A first course in turbulence, MIT press.

30 Liu K., Haworth D. (2011) Development and assessment of POD for analysis of turbulent flow in piston engines, $S A E$ Technical Paper 2011-01-0830.

31 Schlichting H., Gersten K., Gersten K. (2000) Boundary-layer theory, Springer Science \& Business Media.

32 Jainski C., Lu L., Dreizler A., Sick V. (2013) High-speed micro particle image velocimetry studies of boundary-layer flows in a direct-injection engine, International Journal of Engine Research 14, 3, 247-259.

33 Roshko Anatol (1961) Experiments on the flow past a circular cylinder at very high reynolds number, Journal of Fluid Mechanics 10, 03, 345-356.

Cite this article as: F. Hartmann, S. Buhl, F. Gleiss, P. Barth, M. Schild, S. A. Kaiser and C. Hasse (2015). Spatially Resolved Experimental and Numerical Investigation of the Flow through the Intake Port of an Internal Combustion Engine, Oil Gas Sci. Technol 71, 2. 